\title{
BMJ
}

\section{Manchester triage system in paediatric emergency care: prospective observational study}

\author{
M van Veen, PhD student, ${ }^{1}$ Ewout W Steyerberg, professor of medical decision making, ${ }^{2}$ Madelon Ruige, \\ paediatrician, ${ }^{3}$ Alfred H J van Meurs, paediatrician, ${ }^{3}$ Jolt Roukema, resident paediatrics , ${ }^{1}$ Johan van der Lei, \\ professor of medical informatics, ${ }^{4}$ Henriette A Moll, professor of paediatrics ${ }^{1}$
}

\begin{abstract}
${ }^{1}$ Department of Paediatrics, Erasmus Medical Centre, Sophia

Children's Hospital, University

Medical Centre Rotterdam,

PO Box 2060, 3000

CB Rotterdam, Netherlands

${ }^{2}$ Centre for Medical Decision

Making, Public Health,

Erasmus MC, University Medical

Centre Rotterdam, PO Box 2040,

3000 CA Rotterdam, Netherlands

${ }^{3}$ Department of Paediatrics, Haga

Hospital, Juliana Children's

Hospital, PO Box 60605, 2506

LP, Hague, Netherlands

${ }^{4}$ Department of Medical

Informatics, Erasmus MC,

University Medical Centre

Rotterdam, PO Box 2040, 3000

CA Rotterdam, Netherlands

Correspondence to: $\mathrm{H} \mathrm{A}$ Moll

h.a.moll@erasmusmc.nl
\end{abstract}

Cite this as: $B M J$ 2008;337:a1501 doi:10.1136/bmj.a1501

\section{ABSTRACT}

Objective To validate use of the Manchester triage system in paediatric emergency care.

Design Prospective observational study.

Setting Emergency departments of a university hospital and a teaching hospital in the Netherlands, 2006-7.

Participants 17600 children (aged <16) visiting an emergency department over 13 months (university hospital) and seven months (teaching hospital).

Intervention Nurses triaged $16735 / 17600$ patients (95\%) using a computerised Manchester triage system, which calculated urgency levels from the selection of discriminators embedded in flowcharts for presenting problems. Nurses over-ruled the urgency level in 1714 (10\%) children, who were excluded from analysis. Complete data for the reference standard were unavailable in 1467 (9\%) children leaving 13554 patients for analysis.

Main outcome measures Urgency according to the Manchester triage system compared with a predefined and independently assessed reference standard for five urgency levels. This reference standard was based on a combination of vital signs at presentation, potentially life threatening conditions, diagnostic resources, therapeutic interventions, and follow-up. Sensitivity, specificity, and likelihood ratios for high urgency (immediate and very urgent) and $95 \%$ confidence intervals for subgroups based on age, use of flowcharts, and discriminators. Results The Manchester urgency level agreed with the reference standard in 4582 of 13554 (34\%) children; 7311 (54\%) were over-triaged and 1661 (12\%) undertriaged. The likelihood ratio was 3.0 ( $95 \%$ confidence interval 2.8 to 3.2 ) for high urgency and 0.5 (0.4 to 0.5 ) for low urgency; though the likelihood ratios were lower for those presenting with a medical problem (2.3 (2.2 to 2.5) $\mathrm{V}$ 12.0 (7.8 to 18.0) for trauma) and in younger children ( 2.4 (1.9 to 2.9) at 0-3 months $v 5.4$ ( 4.5 to 6.5 ) at 8-16 years). Conclusions The Manchester triage system has moderate validity in paediatric emergency care. It errs on the safe side, with much more over-triage than under-triage compared with an independent reference standard for urgency. Triage of patients with a medical problem or in younger children is particularly difficult.

\section{INTRODUCTION}

Emergency departments need systems to prioritise patients. ${ }^{1}$ Triage should identify those who need immediate attention and those who can safely wait for a longer time or who might not need emergency care. Furthermore, category of urgency related to actual waiting time is used as a quality measure for emergency departments. ${ }^{2}$

As "subjective" triage by nurses without using a system has low sensitivity and specificity, it is important to develop and evaluate triage systems. ${ }^{3}$ The Manchester triage system is a five category triage system based on expert opinion. ${ }^{4}$ The validity of this system has been studied in specific subgroups of adults and was shown to be sensitive in identifying seriously ill patients ("immediate" or "very urgent") and for the detection of high risk chest pain. ${ }^{56}$ Several studies have evaluated inter-rater agreement of triage systems in paediatric emergency care, ${ }^{7-12}$ and some have evaluated trends in resource use and admission. ${ }^{7114}$ One small retrospective study validated the Manchester system in children. ${ }^{15}$

We prospectively validated the Manchester triage system for children in paediatric emergency care. We conducted a large prospective study to allow for sufficient statistical power and detailed evaluation of specific categories of patients.

\section{METHODS}

\section{Study design}

In this prospective observational study we measured validity by comparing the assigned urgency categories of the Manchester triage system with a predefined independent reference classification of urgency.

\section{Study population}

The study included children aged under 16 attending the emergency departments of two large inner city hospitals. The emergency department of the Erasmus MC-Sophia Children's hospital (Rotterdam) is a university paediatric emergency department visited by about 9000 patients per year; the Manchester triage system has been in use here since August 2005. We 
included in our study children who attended from January 2006 to January 2007.

The emergency department of the Haga HospitalJuliana Children's Hospital (The Hague) is a mixed paediatric-adult emergency department of a large teaching hospital visited by nearly 30000 patients per year, of whom about half are children. The Manchester triage system was implemented at this site in 2003; we included children attending from January to July 2006.

Both hospitals are in the southwest of the Netherlands, which has a population of about four million people and an annual birth rate of $47000 .^{16}$

\section{Manchester triage system \\ Emergency department nurses performed a short} assessment and triaged patients using the Manchester triage system. The system is an algorithm based on flowcharts and consists of 52 flowchart diagrams (49 suitable for children) that are specific for the patient's presenting problem. The flowcharts show six key discriminators (life threat, pain, haemorrhage, acuteness of onset, level of consciousness, and temperature) as well as specific discriminators relevant to the presenting problem. Selection of a discriminator indicates one of the five urgency categories, with a maximum waiting time ("immediate" 0 minutes, "very urgent" 10 minutes, "urgent" 60 minutes, "standard" 120 minutes, and "non-urgent" 240 minutes). The presence of key discriminators in different flowcharts will lead to the same level of urgency. Pain is scored on a scale from 0-10 and could assign patients to a higher urgency level. If the nurse does not agree with the assigned urgency category, the system can be overruled. We used a computerised version that uses the official Dutch translation of the flowcharts and discriminators of the first edition (1996). ${ }^{47}$

\section{Data collection}

Patients' characteristics, selected flowcharts, discriminators, and urgency category were recorded in the computerised triage system. Nurses or physicians recorded data concerning vital signs, diagnosis, diagnostic and therapeutic interventions, admission to hospital, and follow-up on structured electronic or

\begin{tabular}{|l|c|c|c|c|c|c|}
\hline & \multicolumn{7}{c|}{ Reference standard } \\
\hline $\begin{array}{l}\text { Manchester } \\
\text { triage system }\end{array}$ & Immediate & $\begin{array}{c}\text { Very } \\
\text { urgent }\end{array}$ & Urgent & Standard & $\begin{array}{c}\text { Non- } \\
\text { urgent }\end{array}$ & Total \\
\hline Immediate & 70 & 22 & 80 & 26 & 7 & 205 \\
\hline Very urgent & 233 & 119 & 1079 & 942 & 524 & 2897 \\
\hline Urgent & 79 & 83 & 1729 & 2278 & 731 & 4900 \\
\hline Standard & 48 & 53 & 1096 & 2621 & 1622 & 5440 \\
\hline Non-urgent & 0 & 0 & 7 & 62 & 43 & 112 \\
\hline Total & 430 & 277 & 3991 & 5929 & 2927 & 13554 \\
$\square>1$ category over-triaged & $\square$ Correct triage & & $\square 1$ category under-triaged \\
\hline 1 category over-triaged & $\square 1$ category under-triaged & & \\
\hline
\end{tabular}

Fig 1 Manchester triage system compared with reference standard paper emergency department forms. Trained medical students gathered and entered the data on a separate database, independent of the triage outcome, using SSPS data entry version 4 . The database was checked for consistency and outliers. Data on laboratory tests were obtained from the hospital information system.

\section{Reference standard}

Before the study we defined a reference standard based on literature and expert opinion. ${ }^{15}$ It consists of a combination of vital signs, diagnosis, diagnostic and therapeutic interventions, and admission to hospital and follow-up. Paediatricians and a paediatric surgeon developed the standard in a meeting before the study started.

Patients were considered to be category 1 (immediate) if they had abnormal vital signs according to the paediatric risk of mortality score (PRISM) ${ }^{18}$ Deviations in heart rate, respiratory rate, and blood pressure predict mortality in children in intensive care. ${ }^{18}$ Hyperthermia (temperature $>41^{\circ} \mathrm{C}$ ) indicates a higher risk for severe bacterial infection. ${ }^{19}$ Temperature, respiratory rate or pulse oximetry, and mental status are routinely recorded and if deviations from normal occur they are related to resource use and admission. ${ }^{2021}$ Nurses fully examined all children; vital signs were measured at the discretion of the nurse or physician. For those presenting with a medical (non-trauma) problem, temperature was measured in $84 \%$, heart rate in $44 \%$, and respiratory rate in $30 \%$. If vital signs were not recorded, they were assumed to be normal.

Patients were considered to be category 2 (very urgent) if their vital signs were within normal range and the presumed diagnosis at the end of their consultation in the emergency department was a potentially life threatening condition (as defined in appendix 1, see bmj.com). Most of these conditions are associated with a high morbidity and mortality and are discussed in the advanced paediatric life support workbook as emergencies. ${ }^{223}$ The expert panel classified aorta dissections and high energy traumas as potentially life threatening conditions. In a systematic review, McGovern et al suggested that patients with an apparently life threatening event (ALTE) should be monitored for 24 hours. ${ }^{24}$

Patients were allocated to category 3 or 4 (urgent or standard) depending on the performed diagnostics, administered treatment, and the scheduled follow-up.

Patients were considered to be category 5 (nonurgent) if they did not require any of the resources. Previous studies on other triage systems for children showed an association between urgency level and resource use and follow-up. Resource use is associated with the urgency level of the emergency severity index (ESI)..$^{713}$

A classification matrix of the reference classification and detailed definitions of the reference standard urgencies are shown in appendices 1 and 2 (see bmj.com). We defined the reference standard for each patient independent of urgency according to the Manchester system and based on a computerised application of the classification matrix. 


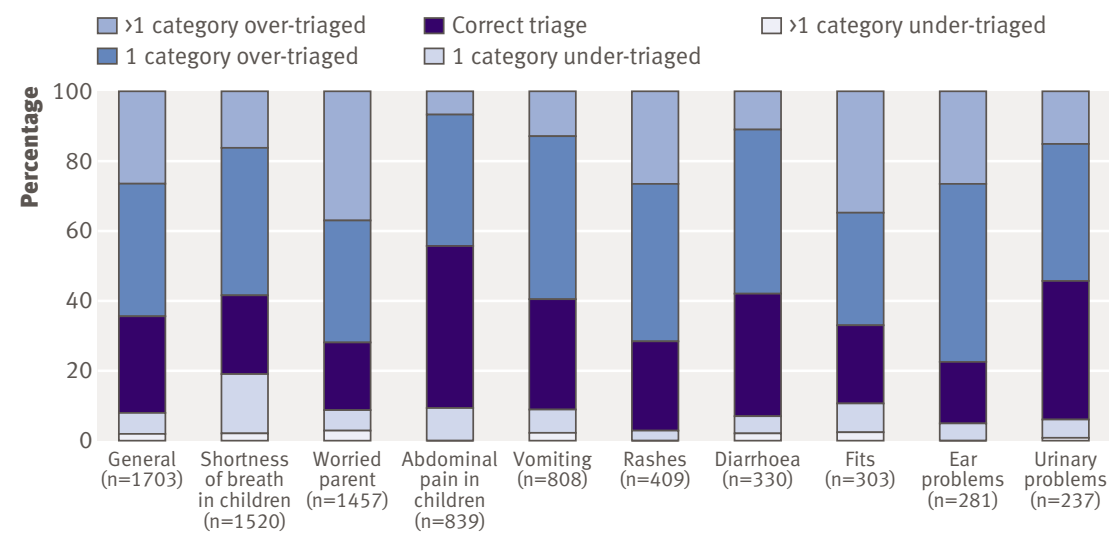

Fig 2 | Ten commonly used medical flowcharts and validity

\section{Sample size}

In our pilot study $1 \%$ of the patients were classified as immediate. ${ }^{15}$ To have at least 100 patients available for assessment of validity in this category, ${ }^{25}$ we set the sample size at a minimum of 10000 patients.

\section{Data analysis}

We validated the Manchester triage system by comparing the assigned urgency category with the category assigned with the reference standard. We defined over-triage and under-triage as the proportions of patients who had a higher or lower urgency category with the Manchester system, respectively, than with the reference standard. ${ }^{15}$

We calculated sensitivity, specificity, and likelihood ratios for classification as high urgency and low urgency (likelihood ratio+=sensitivity/(1-specificity) and likelihood ratio $-=(1-$ sensitivity $) /$ specificity $).{ }^{26}$ Patients categorised as immediate and very urgent were considered as high urgency and those classified as urgent, standard, or non-urgent as low urgency. The validity for subgroups was determined according to age and flowchart. Age was divided into subgroups $<$ 3 months, 3 months- 11 months, $1-3$ years, $4-7$ years, $\geq$ 8 years). We distinguished patients with trauma and medical flowcharts. The trauma flowcharts included limb problems, head injury, major trauma, falls, wounds, injury to the trunk, and assault; all other flowcharts were considered to be medical ones. Commonly used medical flowcharts were considered. We calculated the percentage over-triage and undertriage for patients triaged with commonly used discriminators (fever and recent problem). Secondly, we assessed validity for patients with fever divided into age groups. Analyses were performed using SPSS software (version 14.0.1, SPSS, IL). Sensitivity, specificity, and likelihood ratios with 95\% confidence intervals were calculated with the VassarStats website (http://statline.cbs.nl/statweb). ${ }^{16}$

\section{RESULTS}

Nurses applied the Manchester triage system in 16735 of 17600 children (95\%) who attended the emergency department. The distribution of the reference standard did not differ between those who were or were not triaged $(\mathrm{P}=0.06)$. Nurses over-ruled the urgency category in $1714(10 \%)$; 735 of whom (43\%) had originally been triaged with the Manchester triage system as very urgent compared with $21 \%$ of the patients triaged with the Manchester system overall. Of these children in whom the classification of very urgent was over-ruled, $720(98 \%)$ were downgraded by at least one category.

In the 384 and 509 patients triaged into the urgent and standard categories of the Manchester triage system, $73(19 \%)$ and $22(4.4 \%)$, respectively, were downgraded by at least one category. Fever discriminators $(27 \%)$ and the discriminator of recent problem $(22 \%)$ were often used if the urgency category was overruled.

In 1467 (9\%) children, complete data were unavailable for the reference standard, leaving 13554 for analysis. Distribution of the urgency category among children in whom the reference standard was missing was comparable with that in those without missing data $(\mathrm{P}=0.14)$. Median age was 3.4 years (interquartile range 1.2-8.0), $6631(49 \%)$ children attended the university hospital, $5740(42 \%)$ were female, and 6965 (51\%) were not referred by a general practitioner or medical specialist.

Classification of urgency according to the Manchester triage system and the reference standard agreed in $4582(34 \%)$ children. More children were classified as very urgent with the Manchester system than with the reference standard (2897 (21\%) v $277(2 \%))$. Considerably fewer children were classified as non-urgent with the Manchester system than with the reference standard (112 (1\%) v $2927(22 \%))$ (fig 1).

\section{Validity}

The Manchester urgency level agreed with the reference standard in $34 \% \quad(\mathrm{n}=4582)$. Some 5001 $(37 \%)$ children were over-triaged by one category and $2310(17 \%)$ by more than one category. With the Manchester system 1474 (11\%) were under-triaged by one category and $187(1 \%)$ by more than one category.

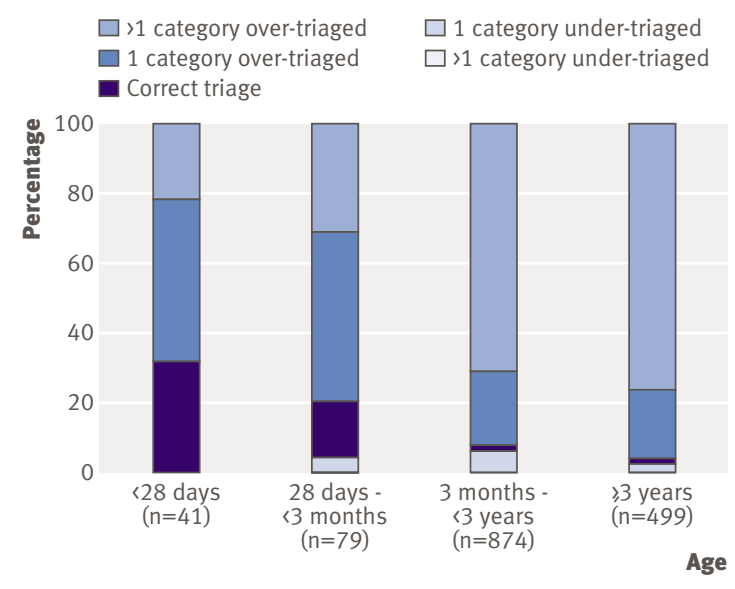

$\overline{\text { Fig } 3 \text { Patients triaged with discriminator fever: relation of age to }}$ validity 
Agreement with the reference standard was particularly low for the very urgent category, with only 119 of 2897 (4\%) classified correctly; 2545 (88\%) were overtriaged and $233(8 \%)$ patients were under-triaged (fig 1 ).

Overall, the Manchester system had a sensitivity of $63 \%(95 \%$ confidence interval $59 \%$ to $66 \%$ ) and a specificity of $79 \%$ (79\% to $80 \%)$ for identifying high urgency patients. The likelihood ratio was $3.0(95 \%$ confidence interval 2.8 to 3.2 ) for a high urgency result and 0.5 (0.4 to 0.5$)$ for a low urgency result. The Manchester system was less sensitive for very young patients (0-3 months) (sensitivity 50\%), resulting in a likelihood ratio+ of 2.4 , while specificity was better for older children $(>4$ years), resulting in higher likelihood ratios. The validity of the Manchester system was lower for children presenting with a medical problem, of whom $61 \%$ were over-triaged and $10 \%$ under-triaged compared with $32 \%$ and 19\%, respectively, for patients presenting with trauma. The likelihood ratio $(+)$ was also lower (table 1).

The validity of the Manchester system in children triaged with medical flowcharts differed considerably between the top 10 medical flowcharts, with poor validity for the worried parent flowchart (19\% correct triage; likelihood ratio+ 0.9 , likelihood ratio- -1.0$)$ (fig 2 and table 1).
Commonly used general discriminators were recent problem $(20 \%)$, pain discriminators (17\%), fever discriminators $(15 \%)$, recent injury $(9 \%)$; commonly used specific discriminators were increased work of breathing (4\%) and persistent vomiting (4\%). Patients triaged with a fever discriminator showed a low validity, especially with increasing age (fig 3 ).

\section{DISCUSSION}

Principal findings and interpretation

The Manchester triage system has an overall moderate validity compared with an independent reference standard. The agreement with the reference standard was $34 \%$, with over-triage in $54 \%$ and under-triage in $12 \%$ (mostly by one category). The sensitivity for high urgency was $63 \%$, implying that $37 \%$ of the patients who actually needed to be seen within 10 minutes were not categorised as that urgent. The specificity was $79 \%$, implying that $21 \%$ low urgency patients were categorised too high. In particular, patients in the very urgent category were over-triaged.

The validity was lower in children presenting with medical problems compared with those presenting with trauma. Any modifications should therefore be particularly targeted for medical problems. Specific discriminators can be considered for their role in the

Table 1 | Sensitivity, specificity, and likelihood ratios with $95 \%$ confidence intervals for different subgroups on age, presenting problem, and medical Manchester triage system flowcharts

\begin{tabular}{|c|c|c|c|c|c|c|c|}
\hline \multirow[b]{2}{*}{ Subgroup } & \multirow{2}{*}{$\begin{array}{c}\text { No of } \\
\text { patients }\end{array}$} & \multicolumn{2}{|c|}{ High urgency \%* } & \multirow[b]{2}{*}{ Sensitivity $†$} & \multirow[b]{2}{*}{ Specificity† } & \multirow[b]{2}{*}{ LR+ } & \multirow[b]{2}{*}{ LR- } \\
\hline & & Manchester & Reference & & & & \\
\hline Overall & 13554 & 23.0 & 5.2 & 63 (59 to 66) & 79 (79 to 80$)$ & 3.0 (2.8 to 3.2$)$ & $0.47(0.43$ to 0.52$)$ \\
\hline \multicolumn{8}{|l|}{ Age: } \\
\hline $0-2$ months & 1033 & 25.0 & 14 & $50(42$ to 58$)$ & 79 (76 to 82$)$ & 2.4 (1.9 to 2.9 ) & $0.63(0.54$ to 0.74$)$ \\
\hline 3-11 months & 1965 & 33.0 & 6.6 & 65 (56 to 73$)$ & 69 (67 to 72$)$ & 2.1 (1.9 to 2.5$)$ & 0.50 (0.39 to 0.63$)$ \\
\hline $1-3$ years & 4427 & 27.0 & 5.7 & $67(61$ to 73$)$ & 75 (74 to 77$)$ & 2.7 (2.5 to 3.0$)$ & $0.43(0.36$ to 0.52$)$ \\
\hline 4-7 years & 2760 & 20.0 & 3.0 & $66(55$ to 76$)$ & 81 (80 to 83$)$ & 3.6 (3.0 to 4.2$)$ & 0.41 (0.31 to 0.56$)$ \\
\hline $8-16$ years & 3369 & 13.0 & 2.8 & 64 (53 to 73$)$ & 88 (87 to 89$)$ & $5.4(4.5$ to 6.5$)$ & $0.41(0.31$ to 0.54$)$ \\
\hline \multicolumn{8}{|l|}{ Presenting problem $\ddagger$ : } \\
\hline Medical & 9774 & 30.0 & 7.0 & 64 (60 to 67$)$ & 72 (71 to 73$)$ & 2.3 (2.2 to 2.5$)$ & $0.50(0.45$ to 0.55$)$ \\
\hline Trauma & 3332 & 4.9 & 0.6 & 55 (32 to 76$)$ & 95 (95 to 96) & 12.0 (7.8 to 18.0$)$ & $0.47(0.29$ to 0.77$)$ \\
\hline \multicolumn{8}{|l|}{ Medical flowchartsł: } \\
\hline General & 1703 & 34.0 & 7.9 & $63(55$ to 71$)$ & 68 (66 to 71$)$ & 2.0 (1.7 to 2.3$)$ & $0.53(0.43$ to 0.67$)$ \\
\hline $\begin{array}{c}\text { Shortness of } \\
\text { breath in children }\end{array}$ & 1520 & 50.0 & 12 & $78(72$ to 84$)$ & $54(51$ to 56$)$ & 1.7 (1.5 to 1.9 ) & $0.40(0.30$ to 0.53$)$ \\
\hline Worried parent & 1457 & 45.0 & 6.0 & $42(32$ to 54$)$ & 55 (52 to 58$)$ & 0.9 (0.7 to 1.2$)$ & $1.0(0.87$ to 1.2$)$ \\
\hline $\begin{array}{l}\text { Abdominal pain } \\
\text { in children }\end{array}$ & 839 & 5.6 & 0.6 & 40 (7 to 83$)$ & 95 (93 to 96) & 7.4 (2.4 to 22$)$ & $0.63(0.31$ to 1.3$)$ \\
\hline Vomiting & 808 & 4.2 & 5.2 & 14 (6 to 29$)$ & 96 (95 to 97$)$ & 3.9 (1.7 to 8.9 ) & $0.89(0.79$ to 1.0$)$ \\
\hline Rashes & 409 & 23.0 & 1.5 & 83 (36 to 99) & 78 (74 to 82$)$ & 3.8 (2.6 to 5.7$)$ & 0.21 (0.036 to 1.3$)$ \\
\hline Diarrhoea & 330 & 6.1 & 5.5 & 44 (22 to 69$)$ & 96 (93 to 98) & 11.6 (5.4 to 25$)$ & 0.58 (0.38 to 0.87$)$ \\
\hline Fits & 303 & 60.0 & 17 & 83 (70 to 91) & 45 (39 to 51$)$ & 1.5 (1.3 to 1.8$)$ & $0.38(0.21$ to 0.69$)$ \\
\hline Ear problems & 281 & 17.0 & 1.1 & 33 (2 to 87 ) & 83 (78 to 87$)$ & 2.0 (0.4 to 10.0$)$ & 0.80 (0.36 to 1.8$)$ \\
\hline Urinary problems & 237 & 28.0 & 2.1 & 80 (30 to 90$)$ & 73 (67 to 79$)$ & 3.0 (1.8 to 4.9$)$ & $0.27(0.047$ to 1.6$)$ \\
\hline
\end{tabular}

$\mathrm{LR+}=$ likelihood ratio for high urgency triage test result, $\mathrm{LR}-=$ likelihood ratio for low urgency triage test result.

*Immediate and very urgent category.

†Sensitivity=high urgency (immediate or very urgent) according to Manchester system/high urgency according to reference standard. Specificity=low urgency (urgent, standard, or non-urgent) according to Manchester system/low urgency according to reference standard.

łFlowcharts available for 13106 (97\%). Selection of the 10 most used medical flowcharts accounts for 80\% (7887/9774) of patients' medical flowcharts. 
triage system. For example, children aged $<3$ months with fever are at greater risk for a serious bacterial infection, whereas children aged $\geq 3$ months with fever might be allocated to a lower urgency category. ${ }^{27}$ Such a modification was incorporated in the emergency severity index (ESI) (version 4), a commonly used triage system in Europe and the United States. ${ }^{28} \mathrm{~A}$ modification of the paediatric CTAS, a Canadian triage system, in which febrile children aged 6-36 months with no signs of toxicity could be triaged to a lower urgency level (from level 3 to 4), has been shown to be safe. ${ }^{29}$

The validity of triage systems depends on the extent to which the system predicts urgency and on the accuracy of the nurse who applies the system (interrater agreement). We previously found a good interrater agreement of the Manchester system in children at our two emergency departments, both for written case scenarios (weighted $\kappa 0.83,95 \%$ confidence interval 0.74 to 0.91 ) and for simultaneous triage of actual patients $(0.65,0.56$ to 0.72$)$ ( $\mathrm{M}$ van Veen, personal communication). We can therefore assume that the validity of the Manchester system compared with the reference standard is mostly due to the predictive value of the system to assess urgency.

\section{Strengths and limitations of the study}

In the Manchester triage system, conditions such as shock, inadequate breathing, compromised airway, and unresponsiveness are used to identify children who need to be seen immediately. For the reference standard we classified children as immediate if blood pressure, heart rate, and respiratory rate were abnormal, if they had a decreased consciousness, or if hyperpyrexia or hypothermia was present. As abnormal vital signs predict mortality in children in critical care units ${ }^{18}$ and the measurement of vital signs is part of triage assessment, they should be used to identify patients who need immediate attention. Our reference standard was based on literature and expert opinion, which admittedly reflects a low grade of evidence. ${ }^{30}$ The goal of seeing patients in the order of their category of urgency is to decrease morbidity and mortality. ${ }^{31}$ Mortality, however, is rare in children presenting at the emergency department and thus cannot be evaluated. Also, differences in morbidity are hard to relate to shorter or longer waiting times.

Furthermore, the reference standard is based on a combination of patients' characteristics collected at the time of presentation and at the end of the consultation in the emergency department. Characteristics gathered at the end of the consultation might be less suitable to define urgency because of possible changes in the patient's condition over time. Assessment of true acuity requires more information than is available at the time of triage.

Our reference standard can therefore be seen only as an approximation of an ideal standard as it was previously used to study the Manchester triage system in paediatric emergency care and had the advantage of classifying patients across five urgency categories. ${ }^{15303233}$

Another limitation of the study is that nurses overruled the Manchester system urgency category in 10\% of the patients. Originally, these patients were often allocated to the very urgent category, which showed a low validity. Inclusion of the $10 \%$ over-ruled patients would probably have lowered the validity of the Manchester system.

Furthermore, data for the reference standard were missing in $9 \%$ of the patients. Selection bias is not likely as the distribution of the Manchester system categories for patients with missing data was similar to that of the patients without missing data.

Finally, the study was performed in a large urban mixed paediatric-adult emergency department and a

Table 2 | Studies on validity of triage systems in emergency care, published 1997-2008

\begin{tabular}{|c|c|c|c|c|c|}
\hline Study & Sample size & Patients/triage system & Study design & Outcome measure & Conclusion \\
\hline \multicolumn{6}{|c|}{ Manchester triage system: adult and paediatric population } \\
\hline Cooke et al ${ }^{5} 1999$, UK & 91 & $\begin{array}{l}\text { Adults admitted to } \\
\text { critical care area }\end{array}$ & Retrospective & Admission to critical care unit & $\begin{array}{l}\text { Sensitive tool for those who need } \\
\text { subsequent admission to critical care }\end{array}$ \\
\hline Speake et $\mathrm{al}^{6} 2003$, UK & 167 & Adults with chest pain & Prospective & Chest pain assessment protocol & Sensitivity $87 \%$, specificity $72 \%$ \\
\hline $\begin{array}{l}\text { Roukema et al }{ }^{15} 2006 \text {, } \\
\text { Netherlands }\end{array}$ & 1065 & Children & Retrospective & $\begin{array}{l}\text { Reference standard based on vital signs, } \\
\text { diagnosis, resource use, admission rate, } \\
\text { and follow-up }\end{array}$ & Sensitivity $63 \%$, specificity $78 \%$ \\
\hline Current study & 13554 & Children & Prospective & $\begin{array}{l}\text { Reference standard based on vital signs, } \\
\text { diagnosis, resource use, admission rate, } \\
\text { and follow-up }\end{array}$ & Sensitivity $63 \%$, specificity $79 \%$ \\
\hline \multicolumn{6}{|c|}{ Other triage systems studied in paediatric population } \\
\hline Maningas et al ${ }^{14} 2006$, US & 7077 & $\begin{array}{l}\text { Soterion rapid triage } \\
\text { system, } 5 \text { level }\end{array}$ & Retrospective & $\begin{array}{l}\text { Admission rate, length of stay, hospital } \\
\text { charges, current procedural terminology }\end{array}$ & $\begin{array}{l}\text { High validity in paediatric patients, }<2 \% \text { of } \\
\text { patients admitted of urgency levels } 4 \text { and } 5\end{array}$ \\
\hline $\begin{array}{l}\text { Gouin et } \mathrm{al}^{13} 2005 \text {, } \\
\text { Canada }\end{array}$ & $807 / 560$ & Paediatric CTAS, 5 level & $\begin{array}{l}\text { Before and after } \\
\text { prospective study }\end{array}$ & $\begin{array}{l}\text { Admission rate, medical interventions, and } \\
\text { PRISA score, comparison with previous } \\
\text { used triage tool ( } 4 \text { level) }\end{array}$ & $\begin{array}{l}\text { Previous triage tool had better ability to } \\
\text { predict admission than paediatric CTAS }\end{array}$ \\
\hline Baumann et al 2005 , US & 510 & ESI (version 3) & $\begin{array}{l}\text { Prospective triage, } \\
\text { retrospective chart } \\
\text { review }\end{array}$ & $\begin{array}{l}\text { Admission rate, resource use, emergency } \\
\text { department length of stay }\end{array}$ & $\begin{array}{l}\text { ESI score predicts resource use, length of } \\
\text { stay, and admission to hospital in children }\end{array}$ \\
\hline
\end{tabular}




\section{WHAT IS ALREADY KNOWN ON THIS TOPIC}

The consensus based five level Manchester triage system is sensitive in identifying seriously ill adults and those with high risk chest pain

Although the system is widely applied, a large prospective study to evaluate the validity on its use in children is lacking

\section{WHAT THIS STUDY ADDS}

In paediatric emergency care the Manchester triage system shows moderate validity but errs on the safe side as the proportion of over-triage is much larger than under-triage

Triage of children with a medical problem or young patients (aged «1 year) was particularly difficult and the system should be specifically modified to cope with such cases

large university paediatric emergency department with $90 \%$ basic paediatric care. Although these two centres might have a relatively larger number of immediate cases, they are likely to be representative of large emergency departments.

\section{Strengths and weaknesses in relation to other studies}

In an earlier retrospective evaluation of the Manchester triage system in paediatric emergency care, we found $40 \%$ correctly triaged, $15 \%$ under-triaged, and $45 \%$ over-triaged.${ }^{15}$ In the present prospective study we found a lower percentage of correct agreement, but the percentage under-triaged patients was also lower. This can be explained by a difference in fractions of immediate cases. ${ }^{15}$ The sensitivity and specificity for high urgency is highly comparable between these two studies.

Other triage systems studied in paediatric emergency care show a high validity (Soterion rapid triage system), ${ }^{14}$ predicted admission (paediatric Canadian emergency department triage and acuity scale),${ }^{13}$ and predicted resource use and length of stay (emergency severity index)..$^{7}$ Although all of these studies used outcome measures to correlate with urgency or to identify the high urgency patients (intensive care admission), they did not define a "reference standard" for urgency (table 2).

The use of an independent reference standard for each patient will allow for further development and evaluation of modifications to the Manchester triage system. When applying the Manchester triage system in paediatric emergency care, users should be aware of its moderate validity. We need to consider and study modifications for specific flowcharts, discriminators, and age groups for which the triage system has a low validity.

\section{Conclusion}

The Manchester triage system shows a moderate validity in paediatric emergency care but errs on the safe side as the percentage over-triage is much larger than under-triage compared with a reference standard for urgency. Triage of patients with a medical problem or younger patients is particularly difficult.

We thank Kevin Mackway-Jones, professor of emergency medicine, Manchester Royal Infirmary, for critical comments on the manuscript, and
Marcel de Wilde, department of medical informatics, Erasmus University Medical Centre, Rotterdam, Netherlands, for technical support.

Contributors: All authors substantially contributed to the conception and design of the study. MvV, EWS, JvdL, MR, AHJvM, and HAM contributed to the data analysis. MvV, HAM, EWS, and JvdL drafted the article and analysed the data. All authors revised it critically for important intellectual content and gave their approval of the final version. HAM is guarantor. Funding: Netherlands Organization for Health Research and Development (ZonMw), and Erasmus University Medical Centre, Rotterdam, Netherlands.

Competing interests: None declared.

Ethical approval: Institutional medical ethics committee; the requirement for informed consent was waived.

Provenance and peer review: Not commissioned; externally peer reviewed.

1 Hostetler MA, Mace S, Brown K, Finkler J, Hernandez D, Krug SE, et al. Emergency department overcrowding and children. Pediatr Emerg Care 2007;23:507-15.

2 Jimenez JG, Murray MJ, Beveridge R, Pons JP, Cortes EA, Garrigos JB, et al. Implementation of the Canadian emergency department triag and acuity scale (CTAS) in the Principality of Andorra: Can triage parameters serve as emergency department quality indicators? CJEM 2003;5:315-22.

3 Adams SL, Fontanarosa PB. Triage of ambulatory patients. JAMA 1996;276:493-4.

4 Mackway-Jones K, ed. Emergency triage. London: BMJ Publishing, 1997.

5 Cooke MW, links S. Does the Manchester triage system detect the critically ill? J Accid Emerg Med 1999;16:179-81.

6 Speake D, Teece S, Mackway-Jones K. Detecting high-risk patients with chest pain. Emerg Nurse 2003;11:19-21.

7 Baumann MR, Strout TD. Evaluation of the emergency severity index (version 3) triage algorithm in pediatric patients. Acad Emerg Med 2005;12:219-24.

8 Bergeron S, Gouin S, Bailey B, Amre DK, Patel H. Agreement among pediatric health care professionals with the pediatric Canadian triage and acuity scale guidelines. Pediatr Emerg Care 2004;20:514-8.

9 Durojaiye L, O'Meara M. A study of triage of paediatric patients in Australia. Emerg Med (Fremantle) 2002;14:67-76.

10 Gravel J, Gouin S, Bailey B, Roy M, Bergeron S, Amre D. Reliability of a computerized version of the pediatric Canadian triage and acuity scale. Acad Emerg Med 2007;14:864-9.

11 11Maldonado T, Avner JR. Triage of the pediatric patient in the emergency department: are we all in agreement? Pediatrics 2004;114:356-60.

12 12Van derWulp I, van Baar ME, Schrijvers AJ. Reliability and validity of the Manchester triage system in a general emergency department patient population in the Netherlands: results of a simulation study. Emerg Med / 2008;25:431-4.

13 Gouin S, Gravel J, Amre DK, Bergeron S. Evaluation of the pediatric Canadian triage and acuity scale in a pediatric ED. Am J Emerg Med 2005;23:243-7.

14 Maningas PA, Hime DA, Parker DE. The use of the Soterion rapid triage system in children presenting to the emergency department. J Emerg Med 2006;31:353-9.

15 Roukema I, Steyerberg EW, van Meurs A, Ruige M, van der Lei I, Moll HA. Validity of the Manchester triage system in paediatric emergency care. Emerg Med / 2006;23:906-10.

16 Statistics Netherlands. Statistics local districts. http://statline.cbs.nl/ statweb.

17 Mackway-Jones K. Triage voor de spoedeisende hulp. Mancheste triage group. Maarsen: Elsevier gezondheidszorg, 2002.

18 Pollack MM, Patel KM, Ruttimann UE. PRISM III: an updated pediatric risk of mortality score. Crit Care Med 1996;24:743-52.

19 Trautner BW, Caviness AC, Gerlacher GR, Demmler G, Macias CG. Prospective evaluation of the risk of serious bacterial infection in children who present to the emergency department with hyperpyrexia (temperature of 106 degrees For higher). Pediatrics 2006;118:34-40.

20 Chamberlain IM, Patel KM, Pollack MM. The pediatric risk of hospital admission score: a second-generation severity-of-illness score for pediatric emergency patients. Pediatrics 2005;115:388-95.

21 Gorelick MH, Lee C, Cronan K, Kost S, Palmer K. Pediatric emergency assessment tool (PEAT): a risk-adjustment measure for pediatric emergency patients. Acad Emerg Med 2001;8:156-62.

22 Advanced Life Support Group, Mackway-Jones K, Molyneux E, Phillips B, Wieteska S. Advanced paediatric life support. London: B MJ Publishing, 2001.

23 Armon K, Stephenson T, MacFaul R, Eccleston P, Werneke U. An evidence and consensus based guideline for acute diarrhoea management. Arch Dis Child 2001;85:132-42.

24 McGovern MC, Smith MB. Causes of apparent life threatening events in infants: a systematic review. Arch Dis Child 2004;89:1043-8. 
25 Vergouwe Y, Steyerberg EW, Eijkemans MJ, Habbema JD. Substantia effective sample sizes were required for external validation studies of predictive logistic regression models. J Clin Epidemiol 2005;58:475-83.

26 Hunink M, Glasziou P, Siegel P, Weeks J, Pliskin J, Elstein A, et al. Decision making in health and medicine: integrating evidence and values. Cambridge: Cambridge University Press, 2001.

27 Sur DK, Bukont EL. Evaluating fever of unidentifiable source in young children. Am Fam Physician 2007;75:1805-11.

28 Gilboy N, Tanabe P, Travers DA. The emergency severity index. Version 4: changes to ESI level 1 and pediatric fever criteria. J Emerg Nurs 2005;31:357-62.
29 Gravel J, Manzano S, Arsenault M. Safety of a modification of the triage level for febrile children 6 to 36 months old using the pediatric Canadian triage and acuity scale. CJEM 2008;10:32-7.

30 Twomey M, Wallis LA, Myers JE. Limitations in validating emergency department triage scales. Emerg Med / 2007;24:477-9.

31 Cooper RJ. Emergency department triage: why we need a research agenda. Ann Emerg Med 2004;44:524-6.

32 Bindman AB. Triage in accident and emergency departments. BMJ 1995;311:404.

33 Windle J, Mackway-Jones K. Don't throw triage out with the bathwater Emerg Med J 2003;20:119-20.

Accepted: 22 July 2008

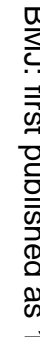

